\title{
Cytoreductive Chemotherapy
}

National Cancer Institute

\section{Source}

National Cancer Institute. Cytoreductive Chemotherapy. NCI Thesaurus. Code C155679.

Drug therapy designed to reduce the number of target cells. 